\title{
Flashbulb memories and the underlying mechanisms of their formation: Toward an emotional-integrative model
}

\author{
CATRIN FINKENAUER, OLIVIER LUMINET, and LYDIA GISLE \\ University of Louvain, Louvain-la-Neuve, Belgium \\ ABDESSADEK EL-AHMADI and MARTIAL VAN DER LINDEN \\ University of Liège, Liège, Belgium \\ and \\ PIERRE PHILIPPOT \\ University of Louvain, Louvain-la-Neuve, Belgium
}

\begin{abstract}
Flashbulb memories (FBMs) are detailed recollections of the context in which people first heard about important events. The present study investigates three models of the formation and maintenance of FBM. Two models have previously been proposed in the literature (Brown \& Kulik, 1977; Conway et al., 1994). A third model of FBM that integrates theories of FBM and recent developments in the field of emotions is proposed. The present study compares these three competing models by investigating the FBMs that Belgian citizens developed upon learning of the unexpected death of their king Baudouin. Structural equation modeling revealed that, as compared to the two previously proposed models, the third model, which takes into account emotional processes, better explains FBM.
\end{abstract}

People have detailed memories for circumstances surrounding their discovery of important national events, such as assassinations of public figures (see, e.g., Brown \& Kulik, 1977; Christianson, 1989; Colegrove, 1899; Winograd \& Killinger, 1983). They remember the specifics of the context in which they first heard about the news: When they heard the news, where they were, what they were doing and with whom, and how they felt upon hearing the news are just a few of the details commonly remembered (see, e.g., Brown \& Kulik, 1977). Brown and Kulik called this phenomenon flashbulb memories (FBMs) to indicate surprise and brevity. Even though FBMs are not as accurate or as permanent as the photographic metaphor suggests (Larsen, 1992; Neisser \& Harsh, 1992), their forget-

Research reported in this paper was supported by FRFC Grant 8.4510.94. from the Belgian National Fund for Scientific Research and by a grant from the Fonds de Développement Scientifique of the University of Louvain. It was also facilitated by the support granted by the Maison des Sciences de l'Homme, Paris, to the Consortium for European Research on Emotion (CERE). We gratefully acknowledge the help of Denise Philippot, Philippe Tilquin, and Annick Beerten in collecting the data. We also wish to thank Geoffrey R. Loftus and two anonymous reviewers who provided invaluable comments and suggestions on an earlier draft. O. L. is Research Assistant at the Belgian National Fund for Scientific Research. A.E. is now at the Department of Psychology, University of Provence, Aix-en-Provence, France. Correspondence concerning this article should be addressed to $C$. Finkenauer, Department of Psychology, University of Louvain, Place Cardinal Mercier, 10, B-1348 Louvain-la-Neuve, Belgium (e-mail: finkenauer@clis. ucl.ac.be)

—Accepted by previous editor, Geoffrey R. Loftus ting curve is far less affected by time than in the case of other types of memories investigated in basic memory research (Bohannon \& Symons, 1992; Christianson, 1989; McCloskey, Wible, \& Cohen, 1988; Pillemer, 1984).

FBMs are cases of autobiographical memories. Because it is well established that emotions have an important influence on autobiographical memory (see, e.g., Conway, 1990; Nigro \& Neisser, 1983; Robinson, 1980), it is imperative to consider their role in FBM formation and maintenance. However, the manner in which emotions affect FBM is probably more complex than that proposed by previous models (see, e.g., Brown \& Kulik, 1977; Conway et al., 1994). The present study investigates the mechanisms underlying FBM, and, more specifically, it compares different models of FBM formation and maintenance. We first review two models of FBM formation and maintenance and their respective supportive evidence. We then describe recent developments in the field of emotions and present a theoretical model of FBM that relies on emotion theory. Subsequently, we present a study examining FBMs for the unexpected death of the Belgian king Baudouin, in which the three models are compared.

\section{A Photographic Model of FBM}

Brown and Kulik (1977) were the first to conceive a theoretical model of FBM formation and maintenance, paralleling the neurophysiological Now-Print! theory (Livingston, 1967). To initialize FBM formation, the original event ${ }^{l}$ has to be new or unexpected and thus must elicit surprise. If an event is routine and common or expected, it is not attended to and, hence, does not lead to surprise. 


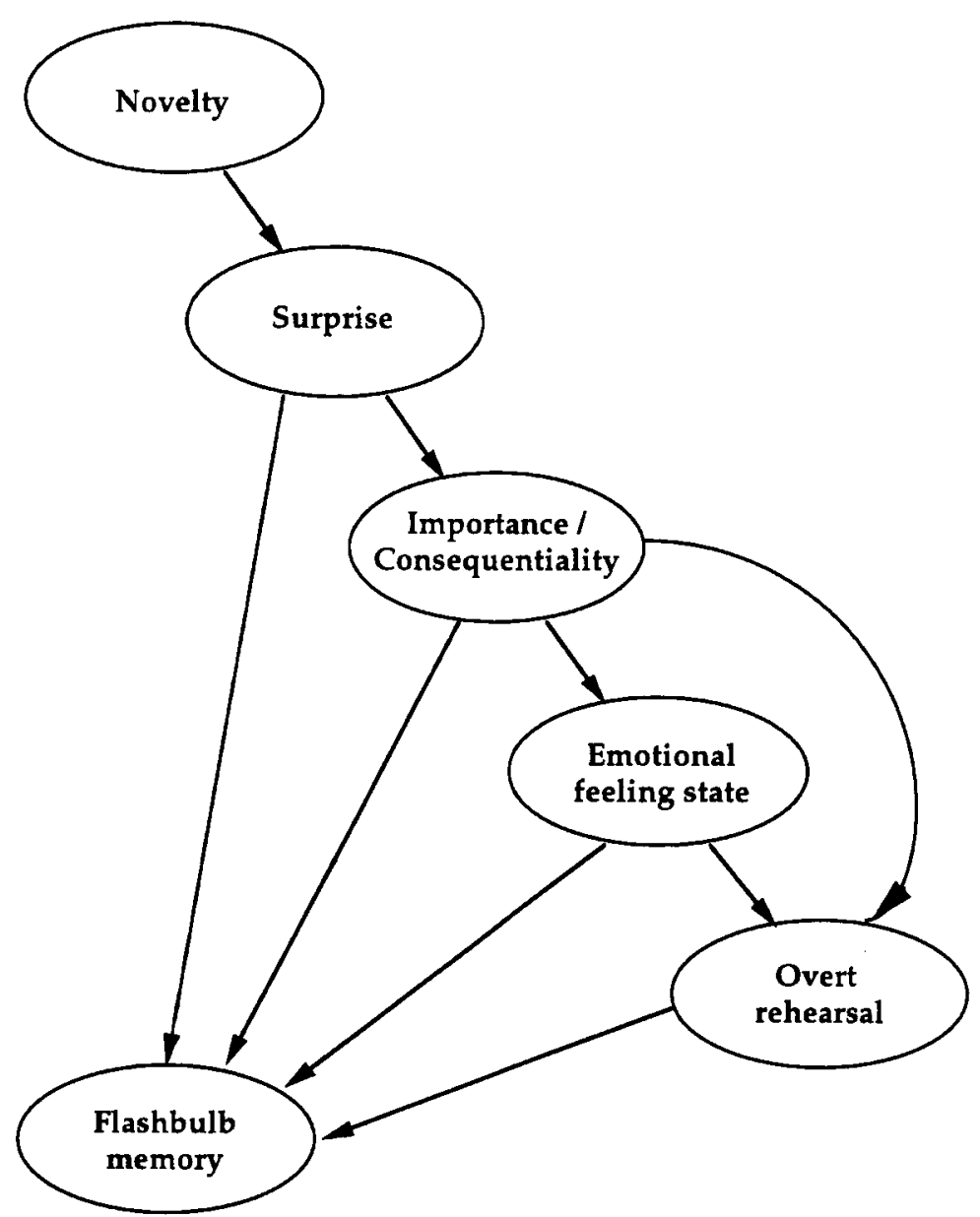

Figure 1. Flashbulb memory formation according to the photographic model.

Consequently, no FB memory is formed. The degree of novelty determines the level of surprise. Given a sufficient level of surprise, the event is then evaluated in terms of consequentiality or personal importance, which, in Brown and Kulik's perspective, is equated with emotional arousal. Both surprise and consequentiality are necessary for FBM formation. Yet, the degree of consequentiality alone determines the degree of completeness of the FBM: the greater the perceived consequentiality, the more detailed the resulting FBM (see Figure 1).

Additionally, Brown and Kulik (1977) propose that rehearsal represents an important mediating variable that leads to further completeness of the FBM. Overt rehearsal takes place during conversations, whereas covert rehearsal takes place when the person thinks about the event. Higher consequentiality is assumed to evoke more frequent rehearsal "of that which is all or part of the flashbulb memory" (p. 85). Rehearsal may affect FBM in two ways. First, it can improve the FBM by reinforcing existing memory traces. Second, it can modify the FBM memory content. For instance, by talking about the news and how they learned about it, people gradually construct a story that matches the communicative demands of the interpersonal situation (see, e.g., Grice, 1975). In this sense, rehearsal is likely to operate on the FBM and its contents (see also Johnson \& Chalfonte, 1994; Neisser, 1982).

To test their theory, the authors selected 10 major events (mostly assassinations). Participants gave a description, as detailed as possible, of the circumstances in which they had learned about the original event, which took place 10 to 30 years before. Participants then rated the consequentiality the event had for them and the frequency with which they had talked about it.

Confirming Brown and Kulik's (1977) model, consequentiality was associated with (1) more detailed FBMs and (2) more overt rehearsal. The rest of the theoretical propositions, however, could not be investigated. On the one hand, the novelty and surprise associated with the original event were not assessed, because these conditions were presumably satisfied by all original events in the study. The extent to which novelty and surprise are critical to the formation of FBMs thus remains unclear. On the other hand, Brown and Kulik did not differentiate between consequentiality and emotional arousal (hereafter referred to as 
emotional feeling state) but used the two concepts interchangeably. Even though the two concepts might overlap, they may be partially independent. The lack of differentiation between the two concepts, however, does not permit establishing whether consequentiality and emotional feeling state independently contribute to the formation of FBM.

Subsequent studies further investigated Brown and $\mathrm{Ku}-$ lik's (1977) suggestions. First, a variety of studies found support for the hypothesis that FBMs are positively associated with consequentiality and surprise (see, e.g., Christianson, 1989; Rubin \& Kozin, 1984). Second, studies confirmed that an intense emotional feeling state is associated with a better recall of FBMs (Bohannon, 1988; Bohannon \& Symons, 1992; Christianson, 1989; Pillemer, 1984; Rubin \& Kozin, 1984). Third, rehearsal, in the form of conversations or media exposure, seems to play an important role in FBM maintenance (see, e.g., Bohannon, 1988; Rubin \& Kozin, 1984).

Overall, these findings provide evidence in favor of Brown and Kulik's (1977) model. Consequentiality, emotional feeling state, and rehearsal are associated with better recall of FBMs (see Figure 1). Additionally, the findings indicate that high levels of surprise lead to a better recall of the reception context. On the basis of this empirical evidence, the first model of FBMs, which we call the photographic model, reasonably assumes that not only the intensity of the emotional feeling state but also the level of surprise directly influences FBM.

However, none of the reported studies assessed all of the factors affecting FBM as proposed by Brown and Kulik (1977). This precludes a valid test and adequate revision of the photographic model of FBM (for a more detailed discussion, see Conway, 1990, 1995; Conway et al., 1994).

\section{A Comprehensive Model of FBM}

Conway et al. (1994) empirically examined the determinants of FBM. They conducted a large test-retest study of FBMs for the resignation of the British prime minister, Margaret Thatcher. Paralleling Brown and Kulik's (1977) original propositions, they investigated the factors assumed to determine FBM formation (surprise, emotional feeling state, and personal importance) and FBM maintenance (rehearsal). Extending Brown and Kulik's propositions, Conway and his colleagues suggested that the rememberer's prior knowledge about Thatcher's government and his or her interest in politics - that is, his or her goals and orientations towards the news-are of central importance for FBM formation. Prior knowledge is predicted to facilitate the organization and assimilation of the incoming information, thereby leading to a more detailed and consistent FBM. Two weeks and then 11 months after Margaret Thatcher's resignation, groups of U.K. and non-U.K. nationals completed an FBM questionnaire requiring a description of the reception context and assessing the hypothesized determinants of FBM: (1) variables influencing FBM formation (i.e., affective reaction, which combined surprise and emotional feeling state, the personal importance the event held for the individual, and prior knowledge of politics) and (2) variables influencing FBM maintenance (i.e., rehearsal through conversations, thoughts, and following the media).

FBMs were operationalized as those memories that were highly consistent from one data collection phase (i.e., after 2 weeks) to the other (i.e., after 11 months). Memories that did not show a high level of consistency were considered as non-FBMs, or ordinary autobiographical memories.

The results confirmed previous studies on FBM (see, e.g., Bohannon, 1988; Brown \& Kulik, 1977; Christianson, 1989; Pillemer, 1984; Rubin \& Kozin, 1984). Participants who had FBMs (1) reported higher levels of initial surprise and affect, (2) rated the event as more important, (3) rehearsed the event more often in the form of thoughts or conversations, and (4) followed the media more frequently than did participants who had no FBMs. Moreover, participants with FBMs had better prior knowledge about Thatcher's government and more interest in politics.

Conway and his colleagues (Conway et al., 1994) then investigated the interrelations between the factors assumed to contribute to the formation and maintenance of FBM by applying the structural equation approach of Bentler (see Bentler, 1980, 1989; Bentler \& Weeks, 1980). Figure 2 depicts the structural relations tested by Conway et al . (1994). The structural equation modeling confirmed that prior knowledge directly determined rehearsal, affect, and importance. Importance determined rehearsal and affect. Because only affect and rehearsal directly determined FBM, knowledge and importance only contributed indirectly to FBM.

On the basis of these findings, Conway et al. (1994) developed a model of memory that we call the comprehensive model. The comprehensive model describes the formation of a memory by three main processes that work over time and can occur independently or in combination. First, prior knowledge about the issue is common to the formation of all memories: It facilitates the assimilation of new information to the existing memory structures. Second, the event is evaluated in terms of personal importance, which is critical for the formation of an FBM. Third, the original event triggers an affective reaction. If the event is perceived as highly important and is associated with high affect, an FBM is formed. If importance does not reach a sufficient level, no relation is established with affect, and no FBM is formed. In this case, however, importance and affective reaction independently contribute to the formation of non-FBMs. Because many subjects in Conway et al.'s (1994) study reported not having rehearsed the news, the comprehensive model assumes that rehearsal does not play a critical - let alone an essentialrole in FBM formation. In fact, in the case of non-FBMs, rehearsal is assumed to help to maintain fragmentary knowledge about the issue. In the case of FBMs, it simply contributes to maintaining their contents.

Conway et al.'s (1994) study represents the first attempt to statistically test FBM formation and maintenance. However, the comprehensive model is mainly based on empirical findings. Also, it does not acknowledge certain 


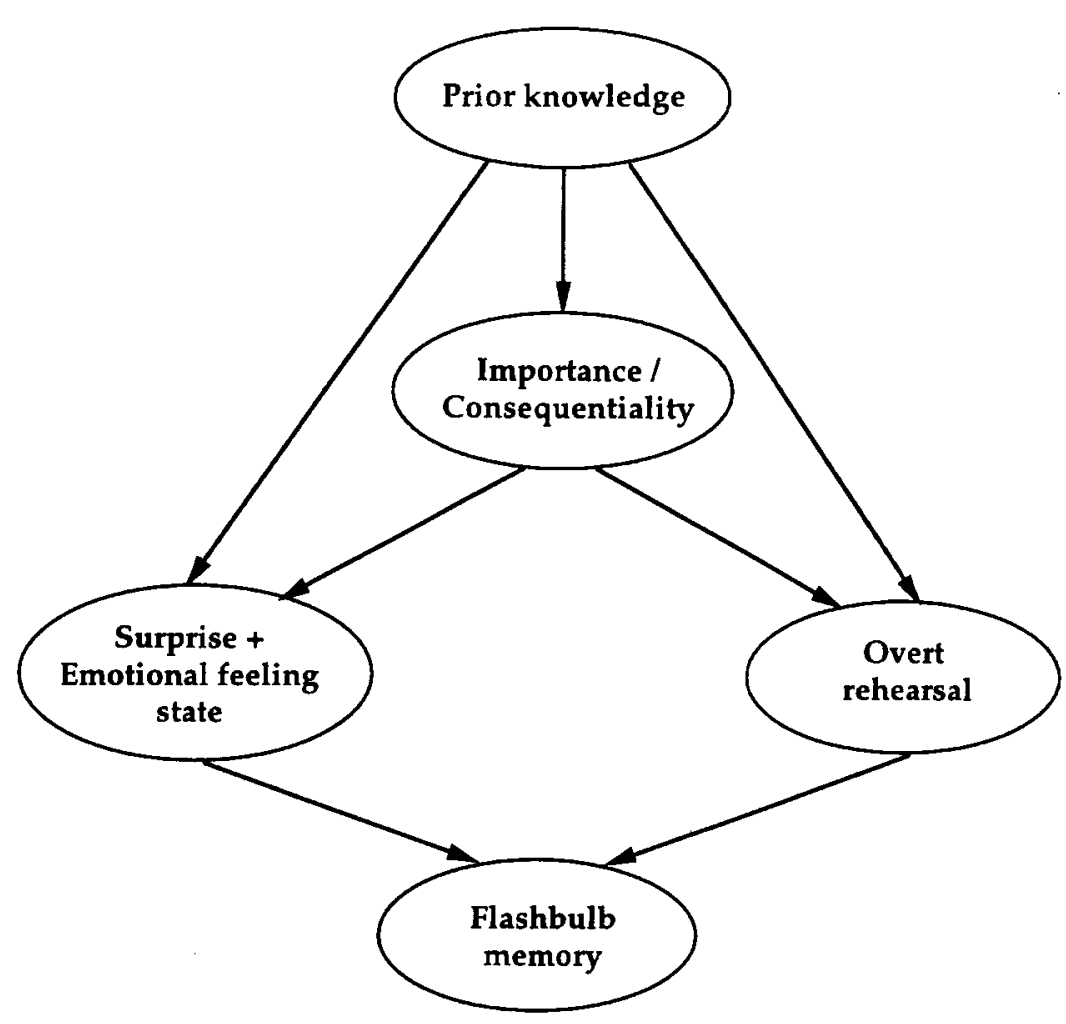

Figure 2. The comprehensive model of flashbulb memory formation and maintenance. Adapted from Conway et al. (1994); copyright 1994 by the Psychonomic Society, Inc.

aspects of the empirical findings. In fact, the structural equation modeling showed that the observed path from rehearsal to FBM was one of the strongest in the model solution (Conway et al., 1994). Affective reaction and rehearsal were the only direct determinants of FBM. However, the comprehensive model assigns only a marginal role to emotions and rehearsal in FBM formation and maintenance. In contrast, we propose that emotion and rehearsal play an important role in the formation and maintenance of FBM. Furthermore, we believe that, to understand this role, it is necessary to consider recent developments of emotion theories. In the following, we examine the emotional processes that may be active in FBM.

\section{Emotion and FBM}

Although common sense associates emotion with a subjective feeling state, emotion scholars consider this concept to be much more complex and to encompass several facets. These facets include information-processing components, response components, and regulatory components (Oatley \& Jenkins, 1996). In the literature on emotion, there is a large consensus on the following processes. Emotion starts with a process of cognitive appraisal. The organism scans internal and external information to assess whether any ongoing event is relevant for its survival, well-being, pursued goals, and/or values (Smith, 1993). The appraisal process is influenced by antecedent per- sonal characteristics, such as beliefs about oneself and the world (see, e.g., Folkman \& Lazarus, 1988), prior experiences and expectations (Fiske \& Taylor, 1991), or attitudes and self-concepts (Lazarus \& Smith, 1988). The environment is appraised along several dimensions. For instance, Leventhal and Scherer (1987) proposed five dimensions: novelty, valence, goal conductiveness, coping potential, and agreement with individual values and standards. Similar dimensions have been proposed by other authors (see, e.g., Smith, 1993). When the outcome of the appraisal process indicates personal relevance, the organism prepares itself to respond adaptively to this environmental challenge; action tendencies are activated (Frijda, 1986). Given the specific situational demands and antecedent personal characteristics, this state of readiness embodies itself in different facets. Physiological changes are activated to support potential actions; expressive, postural, and motoric responses are elicited; cognitive changes, such as attention-narrowing can also be observed (Christianson \& Loftus, 1991). Finally, a subjective feeling state results, which some authors consider to be the result of the cognitive appraisal (see, e.g., Oatley \& Johnson-Laird, 1987) and others the apperception of other facets of emotion (see, e.g., Ekman, 1992). Emotions also elicit longterm and interpersonal processes. Recent studies show that emotions cause people to socially share their emotional experiences (for a review, see Rimé, Philippot, Boca, \& 
Mesquita, 1992) and to seek out more information about what happened. They also reveal that more intense emotional experiences elicit more frequent social sharing than do less intense ones (Philippot \& Rimé, 1998).

From this brief overview, it is obvious that emotion cannot be reduced to a mere subjective feeling state or state of arousal. Therefore, the use of the concept of emotion in FBM research calls for a differentiation between the different facets involved in an emotional reaction. For instance, a major distinction should be made between cognitive appraisal and subjective feeling state. Of particular interest for the field of FBM research, several authors (e.g., Scherer, 1984; Smith \& Ellsworth, 1987) propose that one fundamental type of appraisal consists in the evaluation of novelty. This appraisal specifically leads to an orientation reaction and is clearly involved in emotions such as surprise. Another essential type of appraisal is personal importance (Lazarus \& Smith, 1988; Scherer, 1984). This appraisal is a process of relating one's goals and beliefs to environmental realities. It leads to a more specific emotional feeling state that can consist of one particular emotional state or, as is often the case in real-life events, of complex emotional feeling states.

\section{Applying the Concepts of Appraisal and Subjective Response to the Study of FBM}

Previous models on FBM did not explicitly differentiate between emotional appraisal and emotional feeling states. By paralleling emotion theories, Brown and Kulik (1977) assumed that the appraised novelty and unexpectedness of the original event elicit the subjective feeling state of surprise. Yet, despite its crucial role in the photographic model, previous studies never assessed the appraisal of novelty as such. After the appraisal of novelty, according to Brown and Kulik, consequentiality of the original event is assessed. However, Brown and Kulik did not differentiate between the appraisal of consequentiality and the intensity of emotional feeling state. Conway et al. (1994) did not consider the appraisal of novelty. As in the case of emotion theories, the appraisal of personal importance is assumed to determine the affective reaction. Yet, in their view, surprise and emotional feeling state represent variables of one single latent factor (i.e., affective reaction).

In an attempt to benefit from the conceptual differentiation of emotions, we propose that (1) surprise is a specific consequence of the appraisal of novelty, (2) intensity of emotional feeling state (what Conway et al. [1994] labèled affective reaction) is a general consequence of appraisal processes and, in particular, of personal importance, and (3) surprise and emotional feeling state make differential contributions to FBM formation. On the basis of previous research on FBM (Christianson, 1989; Rubin \& Kozin, 1984), we predict that the level of surprise is a direct determinant of FBM.

The rationale for linking the intensity of emotional feeling state and FBM is more equivocal. At least two paths can be hypothesized. On the one hand, as proposed by the photographic and the comprehensive models, the intensity of emotional feeling state could directly affect FBM. Yet the results of Conway et al.'s (1994) structural analysis revealed a statistically rather weak direct path from intensity of emotional feeling state to FBM. Since Conway et al. (1994) did not differentiate between surprise and emotional feeling state, it remains unclear whether this relation is due to the contribution of surprise to FBM formation or the contribution of the emotional feeling state. On the other hand, it is possible that this rather weak path is due to the fact that intensity of emotional feeling state is only indirectly related to FBM. The link between the intensity of emotional feeling state and FBM may be mediated by rehearsal. Indeed, Brown and Kulik (1977) emphasize that an event of high consequentiality (i.e., emotionally arousing) leads to increased rehearsal. A wealth of studies provide empirical evidence for this assumption (for reviews, see Philippot \& Rimé, 1998; Rimé et al., 1992). They show that social sharing of an event is associated with the intensity of the emotional feeling state elicited during its occurrence. In other words, the intensity of the emotional feeling state determines subsequent rehearsal. It should be noted that these rehearsal processes are likely to address information about the original event rather than information relative to the reception context. Hence, we propose that the intensity of emotional feeling state determines event rehearsal and, as a consequence, the long-term memory of the original event. The memory of the original event, in turn, influences the maintenance of FBM.

In line with Conway et al. (1994) and emotion theories (see, e.g., Lazarus \& Smith, 1988), antecedent personal characteristics are predicted to determine the personal importance the event holds for the individual, the intensity of the emotional feeling state, and subsequent rehearsal.

\section{Summary of the \\ Emotional-Integrative Model of FBM}

The emotional-integrative model of FBM is depicted in Figure 3. It can be seen that the original event is appraised in terms of novelty and personal importance (consequentiality). The appraisal of novelty leads to a reaction of surprise. The appraisal of personal importance, together with the level of surprise, determines the intensity of the emotional feeling state. As is proposed by the comprehensive model, importance, emotional feeling state, and rehearsal are also determined by antecedent personal characteristics. In our study, the antecedent personal characteristics are assessed by the affective attitude toward the king and the royal family. Even though this variable is not equivalent to Conway et al.'s (1994) prior knowledge about politics, we believed that both of these variables reflect the same theoretical construct of antecedent personal characteristics. Thus, we expected personal attitude to evidence the same influence as did prior knowledge in the comprehensive model (Conway et al., 1994). Surprise directly affects FBM. The influence of the emotional feeling state on FBM is twofold. First, as is suggested by previous models, it directly determines FBM. Second and more important, 


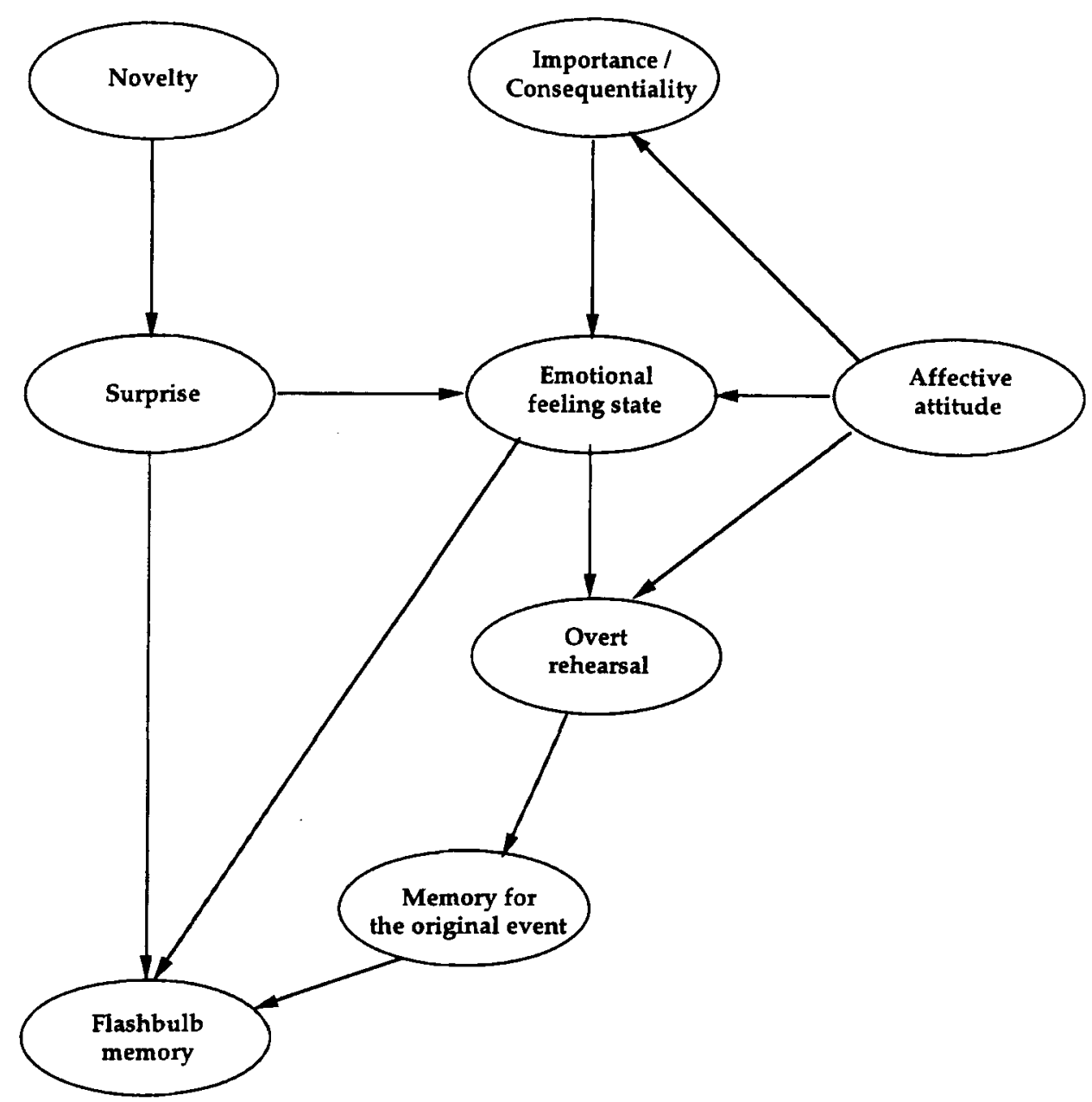

Figure 3. The emotional-integrative model of flashbulb memory formation and maintenance.

it has an indirect impact on FBM: It triggers rehearsal, which, in turn, determines the memory for the original event. Finally, the memory of the original event determines the FBM.

\section{Overview}

The present study tests the respective merits of the three models presented in the introduction (i.e., the photographic model, the comprehensive model, and the emotional-integrative model of FBM) by investigating FBM for the unexpected death of the Belgian king, Baudouin. The death was announced Sunday, August 1, 1993, at approximately 2:30 a.m. The king had died from a heart attack at his vacation residence in Motril, Spain, at about 9:30 p.m. the day before. The news was totally unexpected and had an enormous impact on the Belgian population Baudouin had been king for 42 years. He had a strong unifying impact on a nation that is divided by linguistic and cultural conflicts. The media were flooded with information about his death and its consequences. The Monday following the death, the Belgian papers covered the event on about $60 \%$ of their pages. Six months later, $55 \%$ of the Belgian population reported that it was the event that had marked them most during the year of 1993 (Lits, 1993).

In the present study, a large group of Belgian respondents recalled the circumstances in which they had heard about the king's death some 7-8 months after it occurred. As in Bohannon's study (1988), they were asked to remember specific details about the original event. They then answered questions assessing event novelty, personal importance, surprise, emotional feeling state, frequency of rehearsal, and affective attitude toward the royal family.

\section{METHOD}

\section{Participants}

Three hundred and ninety-four Belgian French-speaking citizens volunteered to participate in the study. Their mean age was 40.5 $(S D=16.74)$, ranging from 13 to 88 years. Respondents came from a large variety of backgrounds. Two hundred and forty were women. The data collection took place 7 to 8 months after the king's death. Questionnaires were distributed in various places (e.g., universities, hospitals, schools) or to experimenters' acquaintances. 


\section{Measures}

The questionnaire consisted of eight sets of questions, assessing the different factors in the described models: (1) flashbulb memory attributes, (2) memory for the original event, (3) overt rehearsal, (4) emotional feeling state, (5) surprise, (6) appraisal of novelty, (7) appraisal of importance, and (8) affective attitude. ${ }^{2}$

Flashbulb memory attributes. FBM was assessed by five items. Respondents answered questions concerning the circumstances in which they first learned of the king's death: the exact time (date and hour) they heard the news (FTI), the place they were (FPL), the people they were with (FPEO), and the ongoing activity they were involved in (FACT). These questions constitute the classical questions used to investigate FBM (see, e.g., Conway et al., 1994). Finally, participants were asked to describe up to five specific details of their personal context when they first heard the news about the king's death (FDET).

The first four items were scored 1 when respondents were able to remember the answer or 0 when they could not. Because previous research shows that almost all respondents are able to remember time, place, people, and ongoing activity (see, e.g., Brown \& Kulik, 1977), we introduced the question assessing specific details in order to prevent a ceiling effect in statistical analyses. Each specific detail was scored 1 when it met one of the following criteria: (1) the reported detail referred to mutable aspects of the environment (e.g., glass of water on $\mathrm{TV}=1$; green carpet in living room $=0$ ) and/or (2) the reported detail referred to the respondent him/herself or his/her position in relation to the environment (e.g., "I was facing the window," or "I was sitting in my favorite chair"). These criteria were chosen to exclude the possibility that respondents simply inferred details on the basis of their familiarity with the environment (e.g., living room, kitchen). Interrater reliability among three independent judges was found to be satisfactory $(r=.95)$. The maximum score for details was 5 .

Memory of the original event. The memory of the original event was assessed by four questions concerning general information related to the king's death that was distributed by the media: the time of death (OTI) (month, day of the week, hour of the day), the exact location of death (OPL), the cause of death (OCAU), and the first person who offered condolences to the queen (OVIS).

Each question was scored from 0 to 2 . A score of 2 indicated that the person was completely correct. A score of 1 indicated that the person was basically but not entirely correct (e.g., location of death was scored 1 when only the city or only the country was recalled and 2 when respondents recalled both). An answer was scored 0 when it was not recalled at all or incorrect (using the same example, neither the city nor the country in which the king had died was recalled, or the wrong country or city was named).

Overt rehearsal. Three items assessed overt rehearsal. Respondents were asked to rate the frequency with which they followed the media (TV, radio, newspapers) after the announcement of the king's death on a 5 -point scale $(1=$ never, $5=$ very often; MED). Two items assessed the communication process. One item concerned the frequency of general conversations about the original event (CGE); the second assessed to what extent conversations concerned specific facts about the original event (CSP). Both items were rated on 5 point scales $(1=$ never, $5=$ more than 6 times, and $1=$ never, $5=$ very often, respectively).

Emotional feeling state. The emotional feeling state was assessed by three items. First, respondents rated their level of upsetness upon learning about the death on a 7 -point scale $(1=$ not upset at all, $7=$ highest level of upsetness of your life; UPS). In addition, two items assessed the emotional impact of the king's death on 7-point bipolar scales ( $1=$ not emotional, $7=$ emotional [EMO], and $1=$ indifferent to, $7=$ shaken up [SHA], respectively).

Surprise. Respondents rated on a 7-point scale the extent to which they were "surprised, amazed, or astonished" upon learning about the king's death $(1=$ not at all, $7=$ very much; SUR $)$.
Appraisal of novelty. Respondents rated on two 7-point bipolar scales how new and salient the news was for them $(1=$ usual, $7=$ unusual [UNUS], and $1=$ common, $7=$ uncommon [UNCO]).

Appraisal of importance and consequentiality. Respondents rated to what extent the event was important for themselves and their life on a 7-point scale ( $1=$ not important at all, $7=$ very important; IMP). In addition, they rated to what extent the original event had consequences for them on a 7 -point scale $(1=$ no consequences at all, $7=$ many consequences; $\mathrm{CON}$ )

Affective attitude. Respondents rated their affective attitude toward the royal family on a 7-point bipolar scale $(1=$ strong antipathy, 7 = strong sympathy; SYM).

\section{Procedure}

Questionnaires were distributed by the authors or by authors' acquaintances. A short text explained that the questions were related to the news of King Baudouin's death. The respondents were asked to remember the details related to the event, the circumstances in which they first heard the news, and their reactions. It was also indicated that there were no right or wrong answers to any question, the experimenters being interested in personal memories of media events.

\section{RESULTS}

The statistical analyses comprised three steps: (1) descriptive statistics, in order to investigate intragroup variability; (2) Pearson correlations, to investigate the relations between observed variables; and (3) structural equation modeling, applied to investigate the supposed causal interrelationships between the different factors.

\section{Descriptive Analyses}

Memory for the original event. As regards the memory of the original event, $80 \%-95 \%$ of the respondents provided the correct answer (scores of 1 or 2 ) to the questions concerning the exact location of death and cause of death. However, only about $50 \%$ of the respondents correctly answered the questions concerning the day of the week the king had died and the person who offered the first condolences to the queen. For the question concerning the exact time the king died ( $\pm 2 h)$, only $38 \%$ of the respondents recalled the correct answer.

Memory for FBM attributes. In contrast, at least $80 \%$ of the respondents recalled the answers to all questions concerning FBM attributes. These results seem to confirm previous findings showing that FBMs remain highly available over long periods of time. As expected, specific idiosyncratic details showed more variability. A majority of respondents recalled at least one changeable detail of the context in which they first heard the news. More specifically, $14.5 \%$ recalled one detail, $11.3 \%$ recalled two details, $15.8 \%$ recalled three details, $13.5 \%$ recalled four details, and $19.3 \%$ recalled five details. Only $25.6 \%$ of the respondents recalled no detail that fulfilled the criteria.

Secondary measures. The results indicate that the Belgian king's death had a strong impact on Belgian citizens. The event led to intense emotional reactions ("upset," $M=4.13, S D=1.71$; "emotional," $M=5.80, S D=1.49$; "shaken up," $M=5.48, S D=1.54$ ). The respondents appraised it as very new and salient ("unusual," $M=6.04$, 
$S D=1.38$; "uncommon," $M=5.36, S D=1.52)$. They also rated the death as highly surprising $(M=5.49, S D=1.83)$ and relatively important $(M=3.18, S D=1.85)$ but as having few consequences for their lives $(M=2.24, S D=$ 1.69). The respondents indicated great sympathy for the royal family $(M=5.32, S D=1.49)$. Finally, the event was often rehearsed. This was the case for both following the media $(M=3.99, S D=1.04)$ and conversations about the event $(M=4.11, S D=1.15$ for frequency of conversations in general, and $M=3.75, S D=1.06$ for extent to which conversations concerned specific facts about the original event). More than half of the respondents (54.4\%) reported talking about the event more than six times.

Bravais-Pearson correlations were obtained between all pairs of variables and are presented in Table 1.

\section{Structural Equation Modeling}

Through the application of structural equation modeling (Bollen, 1989), the photographic model, the comprehensive model, and the emotional-integrative model were investigated. For each model, we generated a structural diagram (see Figures 4, 5, and 6), using the observed variables to indicate the factors intervening in FBM formation and maintenance. We want to point out that the photographic model and the comprehensive model represent, in fact, restricted model versions. Neither model takes all previously proposed variables into account. More specifically, the photographic model does not consider the latent factors affective attitude or prior knowledge, proposed by Conway et al. (1994), and memory of the original event. The comprehensive model does not consider the latent factors novelty, proposed by Brown and Kulik (1977), and memory of the original event. The emotional-integrative model, however, tries, not only to integrate previous propositions by taking all proposed latent factors into account but also to emphasize the role of emotions in FBM.

For each model, the structural diagram represents the causal structure among the hypothesized factors (represented by circles) underlying the observed variables (represented by squares). Each structural diagram includes three types of relationships between factors: (1) direct causal relationships between factors and between factors and their indicators, indicated by straight arrows from the causes, with an arrowhead pointing to the effects; (2) unanalyzed correlations and partial correlations among factors, indicated by a curved line, implying ambiguity about the nature of the relationship between the factors; and (3) null relationships, indicated by an absence of any line between variables, which hypothesize that no theoretical link exists between these variables. In the latter case, it is presumed that any correlation between the variables is entirely explained by their shared relationship with the other causal variables in the model.

The null model specifies no relations among variables, no common factors for the set of input measures, and no covariances among these measures. The usual way of spec- ifying this model is to set to zero the covariances among measures while allowing their variances to be estimated as free parameters.

The first step toward specifying and evaluating a structural model for determinants of FBM consisted in establishing a measurement model (Anderson \& Gerbing, 1988) that represents the correlated factors indexed by their observed variables, listed in Table 1 . The second step consisted in testing theoretical causal relationships specified between the factors. All structural modelings were performed with the SAS CALIS Procedure (Version 6.09; Hartmann, 1990). Model fitting was based on the correlation matrix, following the general analytical strategy advocated by Cudeck (1989). Indicators of fit included first a $\chi^{2}$ test of significance to test the hypothesis that the data were generated by the proposed model or that the model is consistent with the pattern of covariation among the observed variables. Since the $\chi^{2}$ is vulnerable to sample size and/or departure from multivariate normality, a ratio between the model $\chi^{2}$ and the degrees of freedom $(d f)$ is computed. This ratio indicates the fit of the model per $d f$ used. This measure was first proposed in an early application of structural modeling (Wheaton, Muthén, Alwin, \& Sommers, 1977). A threshold value of 2 (Carmines \& McIver, 1981 ) is proposed. Another measure for the discrepancy per $d f$ for a model is the Steiger's root mean square error of approximation (RMSEA; see Steiger, 1990). Practical experience has led researchers to consider that a value of the RMSEA of about 0.05 or less indicates a close fit of the model in relation to the $d f$ (Browne \& Cudeck, 1993). The Goodness of Fit Index (GFI) estimates the extent to which the sample variances and covariances are reproduced by the hypothesized model. A Comparative Fit Index (CFI) is used as an incremental fit index derived from the comparison of the hypothesized model with the null model, in order to determine the amount by which the fit is improved by using the hypothesized model over using the null model (Bentler, 1989). The CFI is a measure of covariation in the data reproduced by the model. For both GFI and CFI, a value greater than .90 indicates an acceptable fit. Akaike's Information Criterion (AIC) (Akaike, 1987) was also introduced for choosing the most parsimonious model. This criterion takes the goodness of fit as well as the number of estimated parameters into account. The model that yields the smallest value of AIC is considered best. Finally, a null model $\chi^{2}$ was used to test the absence of structure in the observed variables. The generalized least squares method was used to estimate the parameters in the presented models (factor loadings, paths coefficients, error variances, correlations). Since age was assumed to be related with all factors (Cohen, Conway, \& Maylor, 1994), the hypothesized models were tested on the basis of the observed correlations from which age had been partialled out. ${ }^{3}$ Once the parameters of the model were estimated, the standardized coefficients were placed on the paths of the structural diagram. These paths can be 


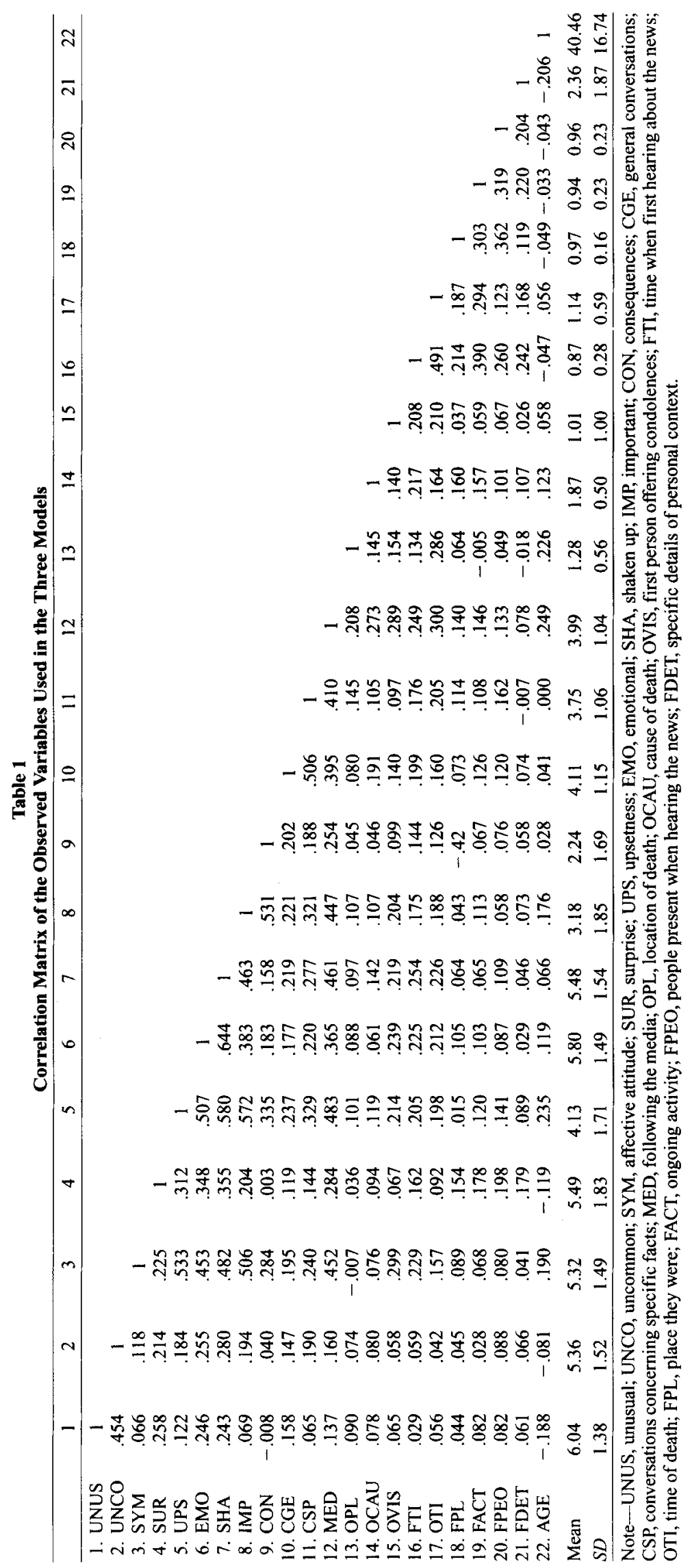


Table 2

Comparison of Generalized Least Square Estimations of the Three Proposed Models

\begin{tabular}{lccc} 
& \multicolumn{2}{c}{ Estimations of the Three Proposed Models } \\
\cline { 2 - 4 } & $\begin{array}{c}\text { Emotional-Integrative } \\
\text { Model }\end{array}$ & $\begin{array}{c}\text { Photographic } \\
\text { Model }\end{array}$ & $\begin{array}{c}\text { Comprehensive } \\
\text { Model }\end{array}$ \\
\hline$\chi^{2}$ & $305.59(177)^{*}$ & $230.86(96)^{*}$ & $205.91(84)^{*}$ \\
$\chi^{2 / d f \text { ratio }}$ & 1.73 & 2.40 & 2.45 \\
Null $\chi^{2}$ & $4,103.44(210)$ & $3,163.86(120)$ & $3,115.24(105)$ \\
GFI & .926 & .926 & .930 \\
CFI & .967 & .956 & .959 \\
AIC & -48.41 & 38.86 & 37.91 \\
RMSEA & 0.043 & 0.060 & 0.061 \\
\hline
\end{tabular}

Note-GFI, goodness of fit; CFI, comparative fit index; AIC, Akaike's information criterion; RMSEA, Steiger's root mean square error of approximation. ${ }^{*} p<.001$.

considered as causality coefficients inferred from the observed correlations. For each of the following figures, the significance level of each parameter is indicated.

A summary of fit indices for the models tested is presented in Table 2. The $\chi^{2}$ statistic for each of the three null models provides a test of the hypothesis that the observed items are uncorrelated. As can be seen in Table 2, this independence hypothesis should be rejected. The large values indicate that more information can be extracted from the data by introducing more parameters into the model. These parameters have been justified by theoretical models (see the introduction).

First, results concerning the emotional-integrative model of FBM are presented. The first column of Table 2 shows the observed fit indices for the emotional-integrative model. As can be seen, the model provides acceptable fit to the data. All items loadings have significant $t$ values (see Figure 4). All causal paths linking factors, except two, are significant (see Figure 4). The two nonsignificant paths were observed for the link between emotional feeling state and FBM and the link between affective attitude and overt rehearsal. However, the emotional-integrative model a priori predicted a strong indirect impact of emotional feeling state on FBM through overt rehearsal and memory of the original event. Also, the fact that overt rehearsal took place in such an overwhelming fashion (Lits, 1993) suggests that people, independently of their affective attitude, could hardly avoid participating in the overt rehearsal surrounding the original event.

As can be seen in Table 2, as compared to the emotionalintegrative model, results were less favorable for the photographic and the comprehensive models of FBM. First, the ratio of $\chi^{2}$ to $d f$ is higher than two (see, e.g., Carmines \& McIver, 1981), indicating a less adequate fit. Second, GFI and CFI are inferior or equivalent for the comprehensive and the photographic models. Finally, the AIC is lowest for the emotional-integrative model $(-48.41$, as compared to 38.86 for the comprehensive model and 37.91 for the photographic model, respectively), suggesting that the emotional-integrative model is more parsimonious than the other two models. On the basis of these analyses, the emotional-integrative model seems to be preferable to the other two. Moreover, some crucial paths proposed by the photographic and the comprehensive models are not significant with respect to the present data (see Figures 5 and 6). In contrast to the assumptions of the photographic model, FBM was not determined either by emotional feeling state or by importance. In contrast to the assumptions of the comprehensive model, FBM was not determined by affect (i.e., surprise and emotional feeling state). The photographic model and the comprehensive model thus constitute a misspecification of the true relationships between the measures in the sense that true paths are omitted and/or false paths are included.

\section{DISCUSSION}

The present study investigated Belgian citizens' recollections of the context in which they first heard about the news of King Baudouin's death. More specifically, our study compared three models of FBM. The structural equation modeling revealed that the emotional-integrative model of FBM should be preferred over the two other competing models proposed in the literature, since it provided the best statistical fit to the data. Additionally, the examination of the observed causal paths indicated that, for the photographic as well as for the comprehensive models, crucial theoretical paths were nonsignificant. Contrary to the prediction of the photographic model, neither importance nor emotional feeling state determined FBM. For the comprehensive model, the affective reaction (i.e., surprise and emotional feeling state) did not determine FBM. However, the comprehensive model assumes that, when importance is associated with affect, an FBM is formed. When applying the model to our dataset, importance strongly determined emotional feeling state, yet emotional feeling state did not directly determine FBM. This result casts major doubts on the critical role of importance in FBM that is promoted by the comprehensive model. For the emotional-integrative model, two paths were nonsignificant. On the one hand, the emotional feeling state did not determine FBM. However, the emotionalintegrative model a priori assumed the link between the emotional feelings state and FBM to be indirect (i.e., mediated by rehearsal) rather than direct. On the other hand, contrary to Conway et al.'s (1994) findings, the affective attitude did not determine rehearsal. Rehearsal took place in an overwhelming fashion (see above). Independently of their personal attitudes, it seems that Belgian citizens could hardly avoid participating in the rehearsal process. It is possible that less intense national events give people the possibility to deliberately choose whether they want to engage in rehearsal or not. In this case, it is likely that the person's attitude and involvement in the issue determines subsequent rehearsal.

Overall, thus, the data of this study support the following sequence of processes in the formation and maintenance of FBM: The appraisal of the novelty causes a reaction of surprise which, in turn, leads to the formation of an FBM. Surprise, together with the appraisal of importance and the affective attitude, determines the intensity of 


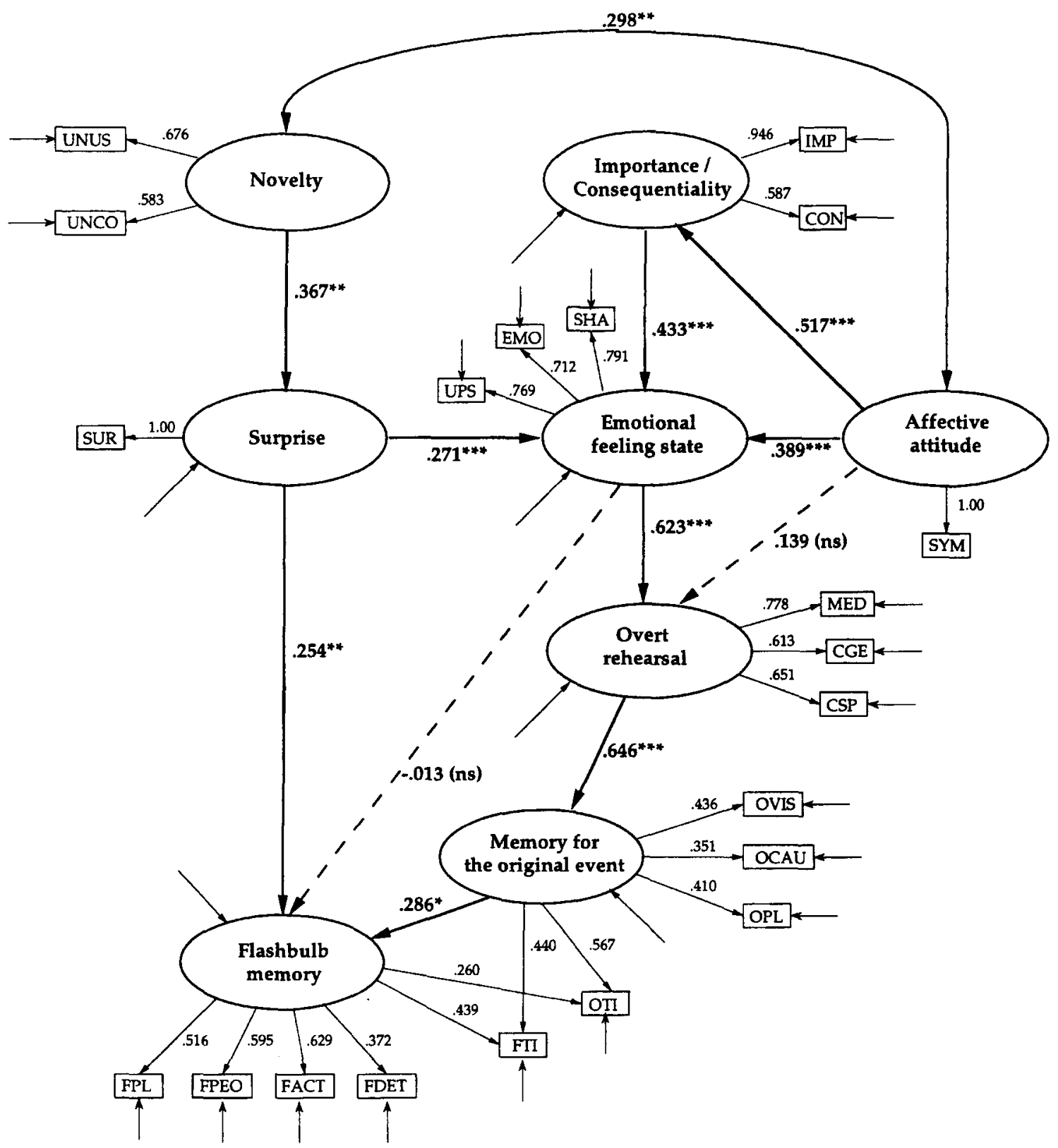

Figure 4. Standardized model parameters derived from the emotional-integrative model of flashbulb memory. ${ }^{*} p<.05$. ${ }^{* *} p<.01 .{ }^{* * *} p<.001$.

the emotional feeling state. This feeling state does not directly affect FBM. Rather, its impact is mediated by two consecutive processes. First, the emotional feeling state triggers rehearsal, which strengthens the memory trace of the original event. Second, the memory of the original event finally determines FBM.

In the following, we examine how the emotional-integrative model relates to the models previously proposed in the literature. We first point out the similarities between the emotional-integrative model and the other models, in order to establish what can be considered as robust findings in the FBM domain. Then, we turn to the specificities of the emotional-integrative model. Finally, we discuss the implications of this study for the understanding of the nature of FBM.

\section{Similarities Between the Three Models of FBM}

First, all three models agree on the set of variables that are hypothesized to influence FBM. These variables are (1) the reaction of surprise upon learning about the original event, (2) the appraisal of importance or consequentiality of the original event, (3) an intense emotional feeling state, and (4) rehearsal. It should be noted that the ensemble of these variables characterizes any new situation an individ- 


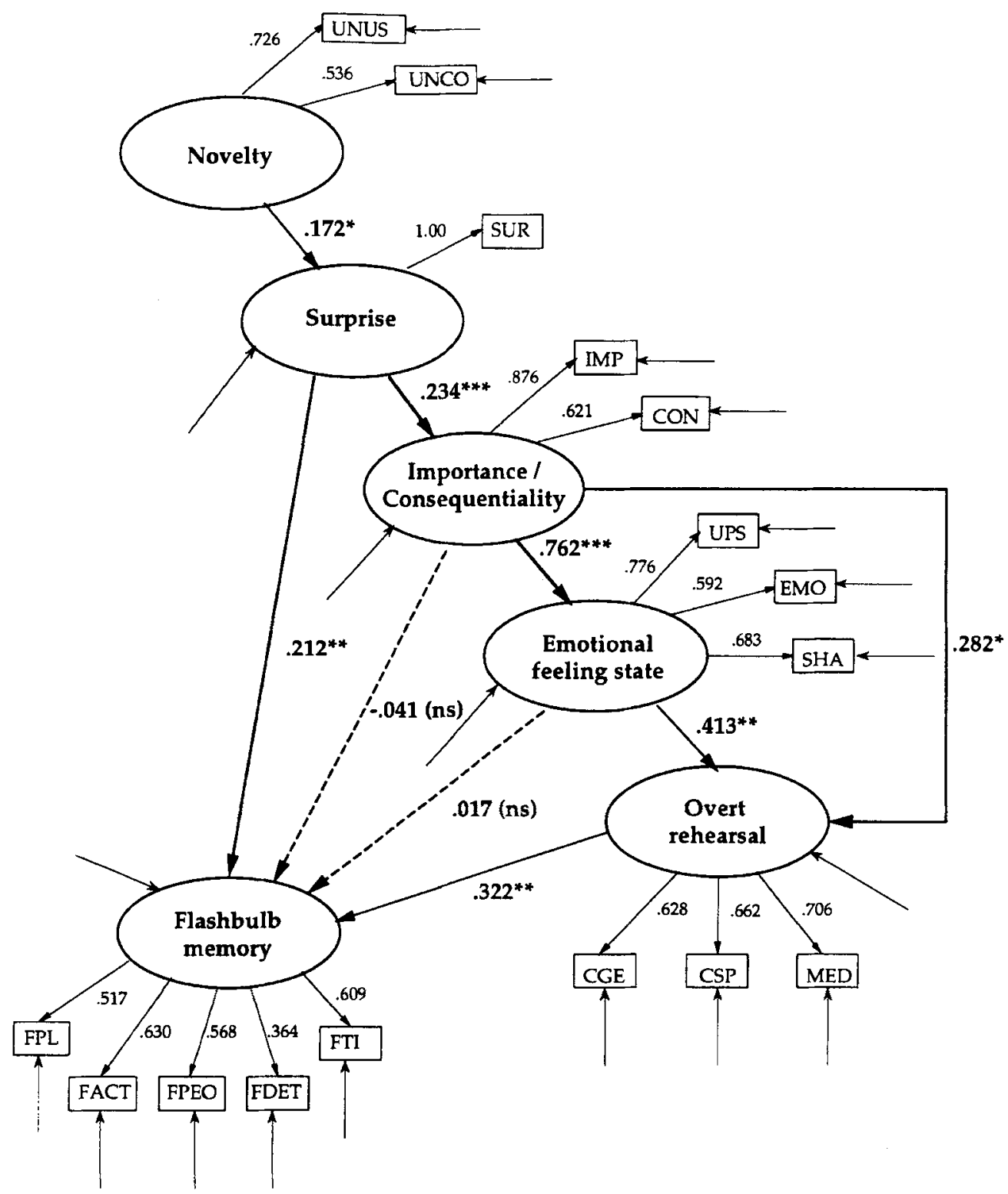

Figure 5. Standardized model parameters derived from the photographic model of nashbulb memory. ${ }^{*} p<.05 .{ }^{* *} p<.01 .{ }^{* * *} p<.001$.

ual is confronted with. New situations include, among others (see Schmidt, 1991), unknown as well as unexpected situations. Hence, there may be a similarity between processing a new situation in memory and FBM formation and maintenance. One could hypothesize a continuum between mildly and extremely new situations in which events leading to FBM would be located at one extreme.

Second, all three models agree that FBMs are initialized by new (or unexpected) situations and that this mechanism has adaptational value (see, e.g., Brown \& Kulik, 1977; Conway, 1995). This assumption corresponds to the novelty-encoding hypothesis (Tulving \& Kroll, 1995), which suggests that novelty is a necessary condition for encoding information in long-term memory. More specifically, this hypothesis predicts that the greater the degree of novelty, (1) the greater the amount of information processed, (2) the more efficient the encoding, and (3) the greater the adaptive significance of its encoding in longterm memory. In this perspective, successful adaptation requires the thorough encoding and anchoring in long-term memory of novel and important (self-relevant) situations. This adaptational process may be enhanced by rehearsal.

Third, the emotional-integrative model and the photographic model explicitly postulate that the appraisal of novelty leads to surprise. The comprehensive model does not include novelty. Yet, Conway et al. (1994) emphasize 


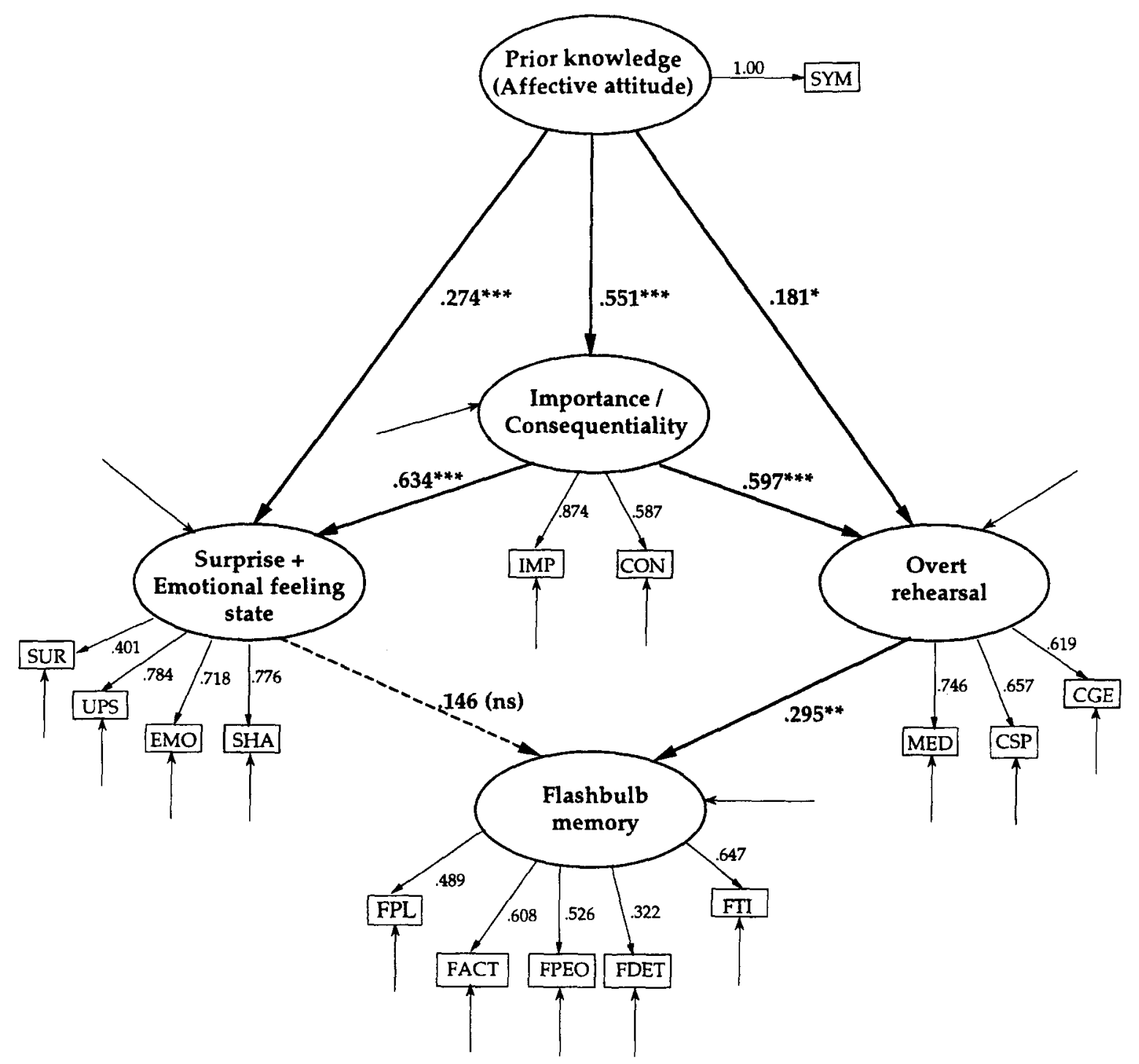

Figure 6. Standardized model parameters derived from the comprehensive model of flashbulb memory. ${ }^{*} p<.05 .{ }^{* *} p<.01$. $\star * * p<.001$.

that Thatcher's resignation was surprising "in the sense that it was wholly out of character and no one had expected her to resign" (p. 340). They thus implied that novelty is necessary to elicit surprise.

Fourth, the emotional-integrative model and the comprehensive model explicitly assume that the appraisal of personal importance or consequentiality determines the intensity of the emotional feeling state (see also Conway, Collins, Gathercole, \& Anderson, 1996). Brown and Kulik (1977) did not differentiate between consequentiality and emotional feeling state, indicating a close link between these two concepts.

Fifth, in all three models, rehearsal is associated with the importance of the event. Yet, although the photographic model postulates this relation, it does not provide a rationale for it. The comprehensive model proposes that the link between importance and rehearsal may reflect the fact that important events are frequently accessed because they are encoded in terms of the self. It remains unclear, however, why this encoding should take place. The emotionalintegrative model suggests an answer to this question. It proposes that events appraised as important continue to elicit intense emotional feeling states, which, in turn, trigger rehearsal (i.e., social sharing and information seeking) to ensure successful adaptation to new and self-relevant situations.

Sixth, in all three models, rehearsal affects FBM. However, whereas Brown and Kulik (1977) proposed that rehearsal affects FBM maintenance, Conway et al. (1994), despite the fact that their data showed that rehearsal strongly affected FBM, disqualified rehearsal as affecting FBM maintenance. Our data shed new light on the role of 
rehearsal in FBM. By empirically validating the path from emotional feeling state to rehearsal and storage in longterm memory to finally FBM, the emotional-integrative model suggests a causal mechanism for the effect of rehearsal on FBM. In fact, this aspect of the model is based on emotion research. Studies showed that, after an initial peak, emotional processes are maintained for very long periods (for reviews, see Philippot \& Rimé, 1998; Rimé et al., 1992). These maintenance processes can be interpersonal, as in the case of social sharing of emotions (see, e.g., Rimé et al., 1992), or intrapersonal, as in the case of mental rumination (see, e.g., Martin \& Tesser, 1989). As long as an event or its consequences bear importance for the individual (Lazarus, 1991), as challenging coping abilities or as questioning personal standards and values (Leventhal \& Scherer, 1987), these processes remain activated, leading to the consolidation of the material in long-term memory.

Finally, the emotional-integrative model and the comprehensive model postulate that antecedent personal characteristics facilitate the assimilation of new information to long-term memory. Even though antecedent personal characteristics were not operationalized in the same fashion as in Conway et al.'s (1994) research, the proposed relations generally held in our data. This suggests that antecedent personal characteristics play an important role in FBMs.

\section{Specificities of the Emotional-Integrative Model}

The present study assessed variables that were only approximated by previous studies. Specifically, (1) it defined and operationalized appraisals of novelty and consequentiality; (2) it distinguished between emotional appraisal and emotional responses (i.e., surprise and emotional feeling state); (3) on the basis of emotion theories, it conceptualized rehearsal as social sharing (i.e., conversations about the emotional event) and information seeking (i.e., following the media); and finally, (4) it assessed the memory of the original event. This approach resulted in the following advances: As detailed above, it provides evidence for the crucial role of the appraisal of novelty for the formation of FBMs. Moreover, it shows that the emotional feeling state upon hearing about the original event does not directly affect FBM formation. Rather, it revealed different mediating processes that accounted for the statistical link between FBM and emotionality. This link-emotional feeling state, rehearsal, memory of the original event, FBM - has already been detailed in the preceding paragraphs. We will now discuss the implications of this last finding.

First, the emotional-integrative model emphasizes social processes in autobiographical memory -in the present case, social sharing. In fact, the role of overt rehearsal in FBM seems to be twofold. On the one hand, it improves the FBM by consolidating existing memory traces (for a detailed discussion of the mechanisms involved in the reactivation of memory, see Johnson \& Chalfonte, 1994).
On the other hand, it may modify the FBM, because it is a constructive process that takes place in a social context (Grice, 1975; Neisser, 1982).

Second, what is rehearsed is not necessarily the content of the FBM itself but rather information about the original event. This is obvious for the ease of rehearsal through following the media. Also, during social sharing, it seems unlikely that participants rehearsed the many details associated with the circumstances in which they heard the news. And, indeed, in the emotional-integrative model, rehearsal is directly linked to the memory of the original event and thereby indirectly linked to FBM.

Third, the present study reveals a relation between memory for the original event and FBM. It is possible that, when learning about the original event, all currently activated information--including the reception context, sensory information, and the original event-is encoded in memory (Tulving \& Kroll, 1995). Thus, both the original event and the reception context would immediately be encoded. Subsequently, during rehearsal of the original event, the reactivation of this information in memory would spread to any associated information and thus to FBM. In this way, rehearsal strengthens the associations between the different elements constituting the memory of the entire experience (Johnson \& Chalfonte, 1994).

Fourth, the mediated path between emotional feeling state and FBM implies that this path only affects FBM maintenance. In contrast, FBM encoding is likely to be determined by the appraisal of novelty and the reaction of surprise elicited thereby. In this case, when confronted with a novel and important event, individuals would encode all the information present at that time (Tulving \& Kroll, 1995). If the information is not rehearsed (i.e., because it has lost its importance), its memory trace should fade away. This proposition is in contrast with the Now Print! mechanism postulated by Brown and Kulik (1977), because this mechanism implies that the information is permanently encoded in memory. Our proposition relies more on what is known of "normal" (i.e., non-FBMs) memory processes.

It has to be noted that our findings rely on retrospective data resulting from a single assessment of memory. In our dataset, the direct impact of the emotional feeling state on FBM is nonsignificant. However, a variety of studies have shown that an intense emotional feeling state is associated with better recall of FBMs (see, e.g., Bohannon, 1988; Pillemer, 1984). It is possible that the immediate impact of emotions on FBM is overshadowed by the emotional aftermath in the form of rehearsal, which may become more important over time. Rehearsal in the form of social sharing occurs within a very brief delay after the emotional episode (Rimé et al., 1992), mostly already during the day on which the event happened. It would thus be important to assess the emotional feeling state immediately after the event happened to establish the impact of emotionality on FBM. Also, it would be necessary to differentiate the im- 
pact of surprise and emotional feeling state on memory. This represents a challenge for researchers, who have to find stimuli that are surprising but not emotional (for a discussion, see Schmidt, 1991).

\section{CONCLUSION}

The present study suggests that FBMs do not imply the existence of a special memory mechanism (see, also, Conway, 1995; McCloskey et al., 1988). It suggests instead that FBMs are the result of ordinary memory mechanisms. However, the great number of details constituting FBMs, their clarity, and their durability suggest that a particularly efficient encoding took place. The clarity and durability of FBMs indicate that these memories are detailed and elaborated representations, likely to give rise to a sense of "pastness" and veracity (Conway, 1995; Conway et al., 1996). The appraisal of novelty played an important role in this process (see, also, Tulving \& Kroll, 1995). Event novelty can be considered a continuum, ranging from familiar to novel. The original events that bring about FBMs would be located at the extreme end of novelty, thereby leading to efficient encoding of the information. From an evolutionary perspective, the efficient encoding of novel information is elementary for the successful adaptation and adjustment to the environment. This assumption parallels theories on emotions. More specifically, contemporary theories view emotions as adaptive responses to the perceived demands of the environment (see, e.g., Frijda, Kuipers, \& ter Schure, 1989). Emotions are represented as multifaceted response sets. In the short run, instantaneous responses-emotional appraisal and feeling state - ensure immediate adaptation, part of which is the efficient encoding and processing of novel information. In the long run, the emotional aftermath-information seeking and rehearsal-contributes to successful adaptation, part of which is the maintenance of important information in long-term memory.

\section{REFERENCES}

AKAIKe, H. (1987). Factor analysis and AIC. Psychometrika, 52, 317-332. ANDERSON, J. C., \& GerBing, D. W. (1988). Structural equation modeling in practice: A review and recommended two-step approach. Psychological Bulletin, 103, 411-423.

BenTLER, P. M. (1980). Multivariate analysis with latent variables: Causal modeling. Annual Review of Psychology, 31, 419-456.

BENTLER, P. M. (1989). EQS: Structural equations program manual. Los Angeles: BMDP Statistical Software.

BENTLER, P. M., \& WeEKS, D. G. (1980). Linear structural equations with latent variables. Psychometrika, 45, 289-308.

BoHANNON, J. N. (1988). Flashbulb memories for the space shuttle disaster: A tale of two theories. Cognition, 29, 179-196.

Bohannon, J. N., \& Symons, L. V. (1992). Flashbulb memories: Confidence, consistency, and quantity. In E. Winograd \& U. Neisser (Eds.), Affect and accuracy in recall: Studies of "flashbulb" memories (pp. 65-91). Cambridge: Cambridge University Press.

Bollen, K. (1989). Structural equations with latent variables. New York: Wiley.
Brown, R., \& KuliK, J. (1977). Flashbulb memories. Cognition, 5, 73-99. Browne, M. W., \& CUDECK, R. (1993). Alternative ways of assessing model fit. In K. A. Bollen \& J. Scott Long (Eds.), Testing structural equation models (pp. 136-162). Newbury Park, CA: Sage.

CARMINES, E. G., \& MCIVER, S. P. (1981). Analyzing models with unobserved variables: Analysis of covariance structures. In G. W. Bohrnstedt \& E. F. Borgatta (Eds.), Social measurement: Current issues (pp. 65-115). Beverly Hills, CA: Sage.

Christianson, S. A. (1989). Flashbulb memories: Special, but not so special. Memory \& Cognition, 17, 435-443.

Christianson, S. A., \& Loftus, E. F. (1991). Remembering emotional events: The fate of detailed information. Cognition \& Emotion, 5, 81-108.

Cohen, G., Conway, M. A., \& MaYLoR, E. A. (1994). Flashbulb memories in older adults. Psychology \& Aging, 9, 454-463.

Colegrove, F. W. (1899). Individual memories. American Journal of Psychology, 10, 228-255.

Conway, M. A. (1990). Autobiographical memory: An introduction. London: Open University Press.

Conway, M. A. (1995). Flashbulb memories. Hove, U.K.: Erlbaum. Conway, M. A., ANDERson, S. J., Larsen, S. F., Donnelly, C. M., MCDaniel, M. A., McClelland, A.G. R., Rawles, R. E., \& Logie, R. H. (1994). The formation of flashbulb memories. Memory \& Cognition, 22, 326-343.

Conway, M. A., Collins, A. F., Gathercole, S. E., \& Anderson, S. J. (1996). Recollections of true and false autobiographical memories. Journal of Experimental Psychology: General, 125, 69-95.

CUDECK, R. (1989). Analysis of correlation matrices using covariance structures. Multivariate Behavioral Research, 18, 147-167.

EkMan, P. (1992). Facial expression of emotion: New findings, new questions. Psychological Science, 3, 34-38.

FISKE, S. T., \& TAYLOR, S. E. (1991). Social cognition. New York: McGraw-Hill.

FolkMAN, S., \& LAZARUS, R. S. (1988). The relationship between coping and emotion: Implications for theory and research. Social Science $\&$ Medicine, 26, 309-317.

FriJda, N. H. (1986). The emotions. Cambridge: Cambridge University Press.

FriJdA, N. H., KuiPers, P., \& Ter SChURE, E. (1989). Relations among emotion, appraisal, and emotional action readiness. Journal of Personality \& Social Psychology, 57, 212-228.

GRICE, H. P. (1975). Logic as conversation. In P. Cole \& J. L. Morgan (Eds.), Syntax and semantics: Vol. 3. Speech acts (pp. 365-372). New York: Seminar Press.

HARTMANN, W. M. (1990). The CALIS procedure: Extended user's guide (SAS Technical Report P-200). Cary, NC: SAS Institute.

Johnson, M. K., \& Chalfonte, B. L. (1994). Binding complex memories: The role of reactivation and the hippocampus. In D. L. Schacter \& E. Tulving (Eds.), Memory systems 1994 (pp. 311-350). Cambridge, MA: MIT Press, Bradford Books.

LARSEN, S. F. (1992). Potential flashbulbs: Memories of ordinary news as the baseline. In E. Winograd \& U. Neisser (Eds.), Affect and accuracy in recall: Studies of "flashbulb" memories (pp. 32-63). New York: Cambridge University Press.

LAZARUS, R. S. (1991). Progress on a cognitive-motivational-relational theory of emotion. American Psychologist, 46, 819-834.

LAZARUS, R. S., \& SMITH, C. A. (1988). Knowledge and appraisal in the cognition-emotion relationship. Cognition \& Emotion, 2, 281-300.

LeVenthal, H., \& SCHERER, K. (1987). The relationship of emotion to cognition: A functional approach to a semantic controversy. Cognition \& Emotion, 1, 3-28.

LiTs, M. (1993). Le Roi est mort . . Emotion et médias [The king is dead ... Emotion and media]. Bruxelles: Editions Vie Ouvrière.

Livingston, R. (1967). Reinforcement. In G. Quarton, T. Melenchunk, \& F. Schmitt (Eds.), The neurosciences: A study program (pp. 499514). New York: Rockfeller University Press.

Martin, L. L., \& Tesser, A (1989). Toward a motivational and structural theory of ruminative thought. In J. S. Uleman \& J. A. Bargh (Eds.), Unintended thought (pp. 306-326). New York: Guilford. 
MCCloskey, M., WiBle, C. G., \& COHEN, N. J. (1988). Is there a special flashbulb memory mechanism? Journal of Experimental Psychology: General, 177, 171-181.

NeISSER, U. (1982). Snapshots or benchmarks? In U. Neisser (Ed.), Memory observed (pp. 43-48). San Francisco: Freeman.

Neisser, U., \& HaRSH, N. (1992). Phantom flashbulbs: False recollections of hearing the news about Challenger. In E. Winograd \& U. Neisser (Eds.), Affect and accuracy in recall: Studies of flashbulb memories (pp. 9-31). New York: Cambridge University Press.

NigRo, G., \& NeIsSER, U. (1983). Point of view in personal memories. Cognitive Psychology, 15, 467-482.

OATLEy, K., \& Jenkins, J. M. (1996). Understanding emotions. Cambridge, MA: Blackwell.

OATLEY, K., \& JoHNSON-LAIRD, P. N. (1987). Towards a cognitive theory of emotion. Cognition \& Emotion, 1, 29-50.

PhilipPot, P., \& Rimé, B. (1998). Social and cognitive processing in emotion: A heuristic for psychopathology. In W. F. Flack \& J. Laird (Eds.), Emotion in psychopathology (pp. 114-129). Oxford: Oxford University Press.

Pillemer, D. B. (1984). Flashbulb memories of the assassination attempt on President Reagan. Cognition, 16, 63-80.

Rimé, B., Philippot, P., BoCA, S., \& MEsquita, B. (1992). Long-lasting cognitive and social consequences of emotion: Social sharing and rumination. In W. Stroebe \& M. Hewstone (Eds.), European review of social psychology (Vol. 3, pp. 225-258). Chichester, U.K.: Wiley.

RoBINSON, J. A. (1980). Affect and retrieval of personal memories. Motivation \& Emotion, 4, 149-174.

Rubin, D. C., \& KozIN, M. (1984). Vivid memories. Cognition, 16, 81-95.

SCHERER, K. (1984). On the nature and function of emotion: A component process approach. In K. Scherer \& P. Ekman (Eds.), Approaches to emotion (pp. 293-317). Hilisdale, NJ: Erlbaum.

SCHMIDT, S. R. (1991). Can we have a distinctive theory of memory? Memory \& Cognition, 19, 523-542.

SMITH, C. A. (1993). Evaluations of what's at stake and what I can do. In B. C. Long \& S. E. Kahn (Eds.), Women, work and coping: A mul- tidisciplinary approach to workplace stress (pp. 238-265). Montreal: McGill-Queen's Press.

Smith, C. A., \& Ellsworth, P. C. (1987). Patterns of appraisal and emotion related to taking an exam. Journal of Personality \& Social Psychology, 52, 475-488.

STEIGER, J. H. (1990). Structural model evaluation and modification: An interval estimation approach. Multivariate Behavioral Research, 25, 173-180.

Tulving, E., \& Kroll, N. (1995). Novelty assessment in the brain and long-term memory encoding. Psychonomic Bulletin \& Review, 2 , 387-390

Wheaton, D. E., Muthén, B., Alwin, D. F., \& Sommers, G. F. (1977) Assessing reliability and stability in panel models. In D. R. Heise (Ed.), Sociological methodology (pp. 84-136). San Francisco: Jossey Bass.

WinOGRAD, E., \& Killinger, W. A. (1983). Relating age at encoding in early childhood to adult recall: Development of flashbulb memories. Journal of Experimental Psychology: General, 112, 413-422.

\section{NOTES}

1. Throughout this article, we will refer to the original event when talking about the news itself. This is to distinguish the news from the reception context - that is, the circumstances surrounding the discovery of the news.

2 . The sequence of the different sets of questions in the original questionnaire was as follows: (1) memory for the original event, (2) flashbulb memory, (3) surprise and emotional feeling state, (4) overt rehearsal, importance, and affective attitude, and (5) demographic questions concerning gender, age, nationality, and educational level.

3. Analyses revealed that statistically controlling for age did not affect the global goodness-of-fit indexes (i.e., $\chi^{2}, \chi^{2 / d f}$ ratio, GFI, CFI, AIC, and RMSEA) in a significant manner.

(Manuscript received September 25, 1996; revision accepted for publication February 6, 1997.) 